\title{
A COMPARATIVE STUDY BETWEEN WATER-GAP AND AIR-GAP DISTILLATION MEMBRANES FOR REMOVAL OF SALTS FROM SALINE WATER BY DESALINATION METHOD
}

\author{
LAURENTIU TATARU ${ }^{* *}$, VALENTIN NEDEFF ${ }^{1,2}$, NARCIS BARSAN ${ }^{1}$, MIRELA \\ PANAINTE-LEHADUS ${ }^{1}$, EMILIAN MOSNEGUTU ${ }^{1}$, DANA CHITIMUS ${ }^{1}$, FLORINA \\ FABIAN $^{1}$ \\ ${ }^{I}$ Department of Environmental Engineering and Mechanical Engineering, "Vasile \\ Alecsandri" University of Bacau, Romania \\ ${ }^{2}$ The Academy of Agricultural and Forestry Sciences "Gheorghe Ionescu, Sisesti, Bucharest, \\ Romania
}

\begin{abstract}
The water deficit for consumption in various daily activities is more pronounced especially in countries where rainfall is low or in those areas where water demand is higher than available resources. This paper is a comparison between the airgap and water-gap distillation method. The results of the study have shown that the water-based distillation method can be more efficient, as the volume of permeate obtained is higher in relation to the increase in the flow temperature. The results obtained as well as the comparison of the advantages related to the two membrane distillation processes will be presented in the present paper.
\end{abstract}

Keywords: Distillation membranes, desalination, saltwater, water-gap membrane, air-gap membrane, salt removal.

\section{INTRODUCTION}

Until nowadays, the classical purification methods encountered at the treatment plants have shown a certain yield, depending on the wastewater contents. Over time, the build-up of pollutants that have reached sewer networks and, ultimately, wastewater treatment plants have begun to put the purification processes into difficulty [1-3].

Thus, purification methods such as flocculation, coagulation, precipitation or mechanical methods: decanting, filtering with simple filters, etc., cannot cope with the increase in the concentrations of organic and inorganic matter in the wastewater [4].

If wastewater treatment plants have low capacities to engage and the population of wastewater cities is growing, urgent implementation of filtering methods and techniques that are effective in terms of procurement and cost recovery is needed. After the first purification steps are carried out, prefilters and filtrations can be applied to retain larger particles $[3,4]$, then an ideal and viable solution that is part of modern depollution technology is the technological membrane [5].

\footnotetext{
* Corresponding author, email: tataru_lauri@yahoo.com

(C) 2018 Alma Mater Publishing House
} 
This paper includes a study on the use of organic distillation membranes in order to retain salt from sea water. Some of the most important methods by which the salt can be retained on membranes are: air-gap distillation (AGMD), direct contact distillation, vacuum distillation and WGMD [6].

The paper presents the difference between the efficiency of two of the before mentioned methods, namely AGMD and WGMD, in terms of both the volume of water produced by distillation and other advantages provided by each method. The water-desalination method is called WGMD (water gap membrane distilation) and the air gap membrane distilation is AGMD (air gap membrane distillation) method.

Molecular water can pass through the membranes only as vapor, but the membranes must be hydrophobic, porous, and water vapor is water of very high purity, the separation process being driven by the difference in cold and hot vapor pressure from both sides of the membrane configuration and the obtained permeate increases with increasing transmembrane pressure [7-13].

Hitsov et al. [14] found in the experiments that the air layer distillation method is more advantageous than direct contact (DCMD): an important aspect refers to the energy that changes in the membrane module, part of it is lost by evaporation and the other as sensitive energy, when the supply liquid is distributed in the circuit (Figure 1) [14].

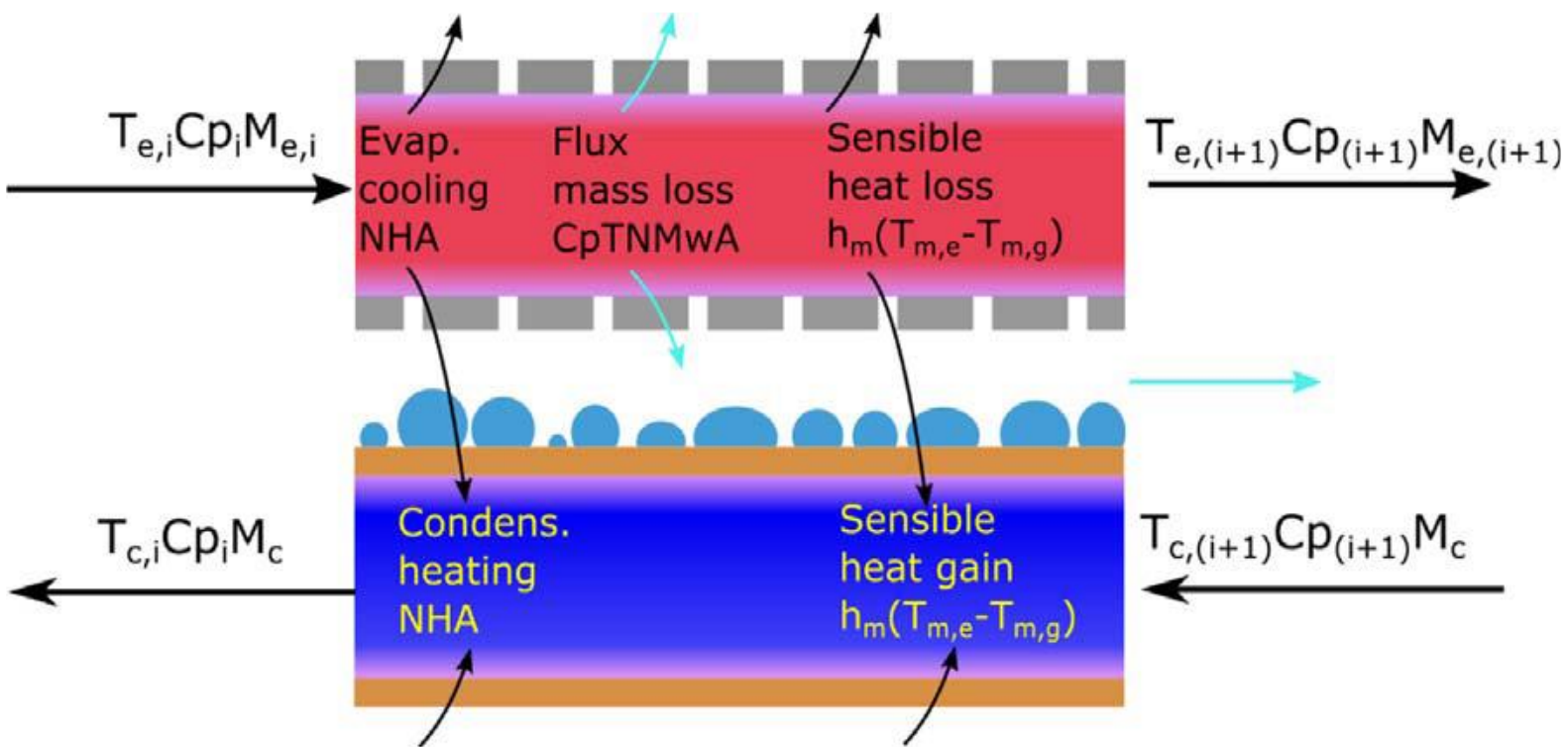

Fig. 1. The mass transfer balance for each section [14]:

$\mathrm{T}_{\mathrm{e}}$ - the evaporation of temperature; $\mathrm{Cp}$ - specific heat capacity; $\mathrm{Mw}$ - molecular weight; $\mathrm{N}$ - flow of membrane fluid; A - membrane surface; h - local transfer factor.

The indices e, c, m and i represent the evaporation channel, cooling channel, membrane and section number. If the energy of the module is limited only by the input energy, then the air-layer distillation method (AGMD) is more advantageous because the losses are much lower due to low thermal conductivity. In this case, the flow of permeate is higher and this is noticeably important for large-scale applications [14].

Abdullah Alkhudhiri and his collaborators [15] have used three hydrophobic PTFE membranes (due to high chemical resistance to chemical contact) with pore sizes of $0.2,0.45$ and $1 \mu \mathrm{m}$, respectively, in the AGMD configuration (Figure 2) [14]. A thermal resistance was used to heat the supply liquid, being isolated to avoid heat loss. The flow of the liquid was kept at $50{ }^{\circ} \mathrm{C}$, being $1.5 \mathrm{~L} / \mathrm{min}$. A cold bath maintained cold water at the desired temperature (required for the condensation process) and $10^{\circ} \mathrm{C}$ at a flow rate of $8.5 \mathrm{~L} / \mathrm{min}$ [15].

Figure 2 represents the scheme of the desalination plant used in this study and consists of the following: the feed tank, the heater, the heat resistance of the liquid heating, the thermocouple, the peristaltic pump, the flowmeter, the pressure gauge, the membrane module, the chiller (necessary for distillation).

PTFE membranes, used in the study presented by Abdullah Alkhudhiri and his collaborators [15], have shown a decrease in permeate flow with increasing salt concentration in the feed water. This leads to the foulling of the 
membrane pores due to the polarization of temperature, viscosity and the change of the layer of matter deposited on the surface of the membrane [15].

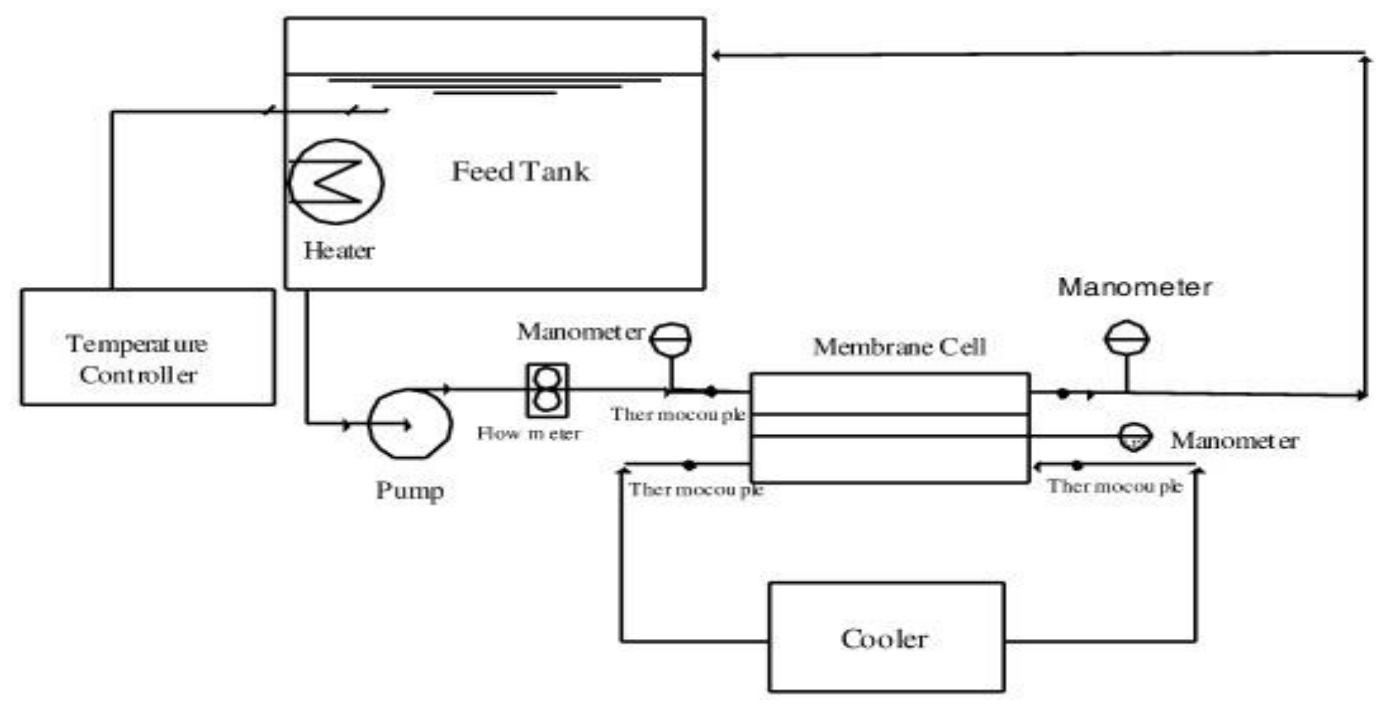

Fig. 2. Diagram of the AGMD configuration presented in this study [15].

Another conclusion from this study is another disadvantage of the AGMD configuration: energy consumption increased with the increase in salt concentration, which leads to an increase in the boiling point [15]. Another study was conducted by A.S. Alsaadi [16], which presented a solution to solve the permeate flux decline mentioned in Abdullah Alkhudhiri's paper [15]: use of the multistage AGMD configuration. In this case, each stage has 18-24 stages, placed in series in order to maintain the same pressure on each step [16].

In the AGMD configuration, the air layer of thickness between 2 and $10 \mathrm{~mm}$ provides the required space for condensation between the membrane and the condensate surface. The transfer resistance of the process is given in this case by the non-condensable gases that appear in this layer and the vapors resulting from the hot part of the membrane module must pass through both the air layer and the membrane pores and eventually turn into water, at the cold surface level [16-20].

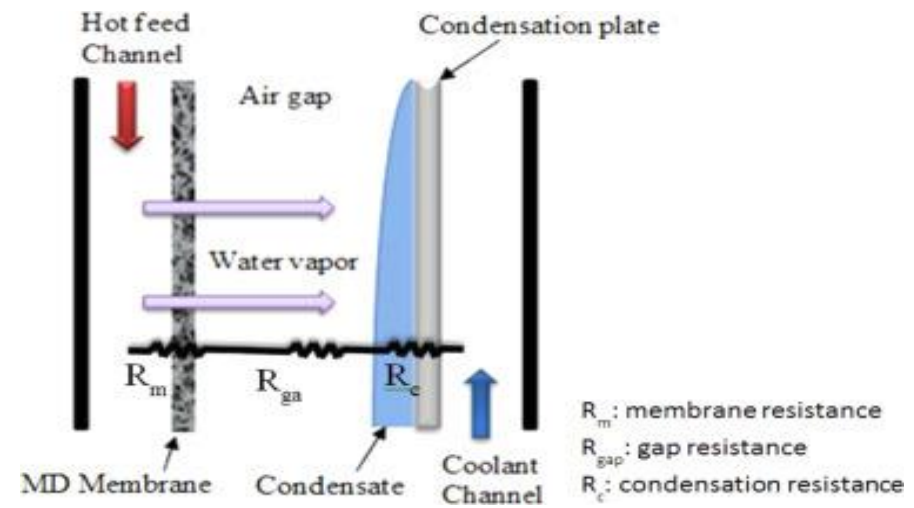

Fig. 3. Strength of mass transfer at the passage of fluid through the vertical configuration of the module [16].

Figure 3 shows a part of the membrane module where the three resistances are found: the membrane resistance which must provide for the most dense time of ultrafiltration, the strength of the gap where the best conditions favorable to the condensation process must be ensured, respectively the condensation resistance, depending on the temperature of the cold and hot liquids. Researchers like M. Essalhi and M. Khayet [20] used a hydrophilic membrane to desalinate, but instead used the water layer instead of the air layer. They found that the flow of 
permeate increased as a result of reducing heat loss by $6.6 \%$. The study of these researchers has shown that WGMD desalination of water is more efficient both in terms of energy consumption and increased permeate flow due to the filling of the space between the cold and the hot water phase [20].

\section{EXPERIMENTAL METHOD FOR THE USE OF WGMD AND AGMD CONFIGURATIONS IN DESALINATION}

\subsection{Desalination using the air and water-layering method}

Regardless of configuration, Atia E. Khalifa [21] conducted a detailed study on desalination. It compared the results obtained by the two methods (AGMD and WGMD). The membrane module components were the same in both cases, only the interface of the module being changed so that the permeate collection is made from the top of the module (WGMD) and its bottom (when the configuration used is AGMD). Figure 4 shows the membrane module, exploded as a whole, and in Figure 5, the assembly of the membrane components required in the study by Atia E. Khalifa [21].

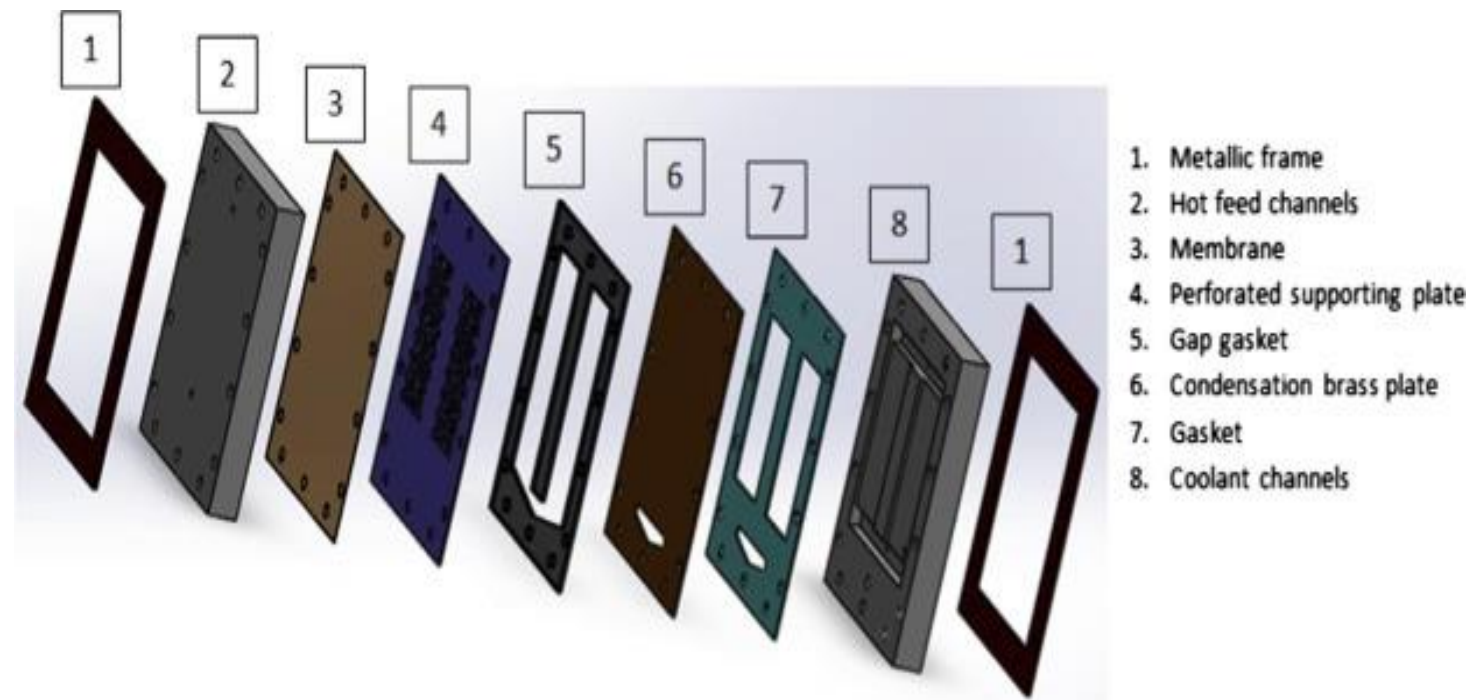

Fig. 4. Exploded view of membrane module components [20].

The components of the membrane module are shown in Figure 4. Each assembled element must be preceded by a rubber layer to avoid wear on both the membrane and the plastic parts due to long-term operation and high temperature. The metal frame is represented by the outer parts of the module because they are most often subject to mechanical action.

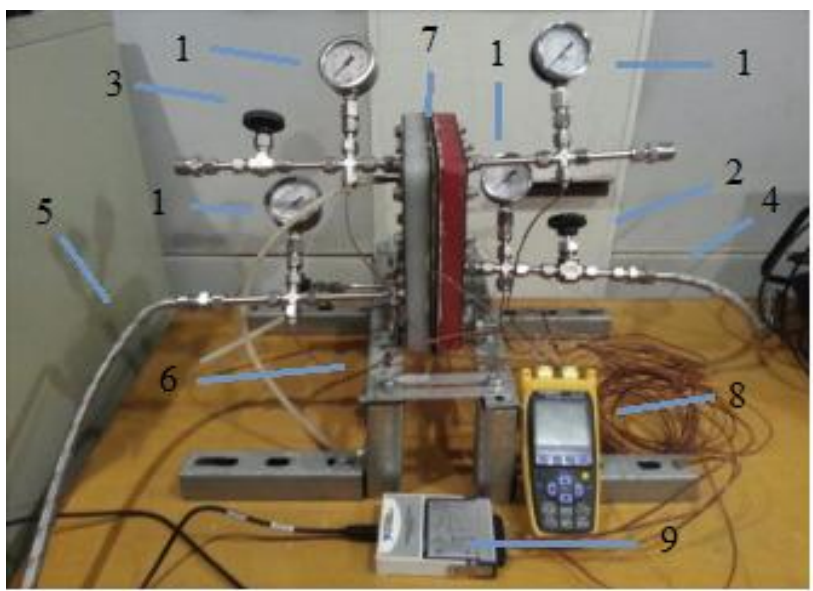
$1=$ gauge manometers
$2=$ valve for hot water recirculation
$3=$ valve for cold water recirculation
$4=$ heated fluid pipe
$5=$ cold fluid pipe
$6=$ membrane suport
$7=$ membrane module
$8=$ recording system temperatures
$9=$ measuring and recording resistances
in the membrane module

Fig. 5. Overall view of the module used in this study [20]. 


\subsection{Experimental research methodology for desalination using the two configurations}

Using a hydrophobic membrane with an effective work area of $0.00724 \mathrm{~m}^{2}$, Atia E. Khalifa [21] conducted a study to see under what conditions and what parameters established that the water-desalination method is more efficient than the method with air layer (AGMD). It used a metal plate for the condensation process when the hot liquid in contact with the metal plate turns into vapor.

Through the thickness of the gaskets, the thickness of the module layer was determined. All components have been screwed together to avoid water leakage. When the hot water reaches the metal plate, it turns into drops of water (permeate) collected from the top or bottom, depending on the configuration [21].

The desalination process is fully controlled so that 4 thermocouples are mounted at the input mode and the flow of liquid is measured by flowmeters. The supply of cold water and hot water is done by keeping the desired temperatures by means of a thermal resistance, respectively a cooling bath [15].

In the case of this type of membrane, the main advantage is that the diaphragm module can be easily manipulated, being supported only on a metal frame, without the difficulty in running the process. The membrane type used by Atia E. Khalifa [21] is PTFE with a porosity of $80 \%$, a pore size of $0.45 \mu \mathrm{m}$ and a membrane thickness of $0.15 \mathrm{~mm}$ at a contact angle of $140^{\circ}$. The flow rate determined the hot and cold water inlet pressure, around 0-0.3 bar [21].

Determination of efficiency for the two types of configurations used was given by the following parameters: feed temperatures, cold and hot water flow, concentration of the feed water, thickness of the air or water layer, composition of the support plate. At the same time, the temperature difference of the water or air layer was investigated, as this cannot be the same for the water and air layer [21].

\section{RESULTS AND DISCUSSIONS}

\subsection{The influence of the supply temperature for the two configurations (AGMD and WGMD)}

Atia E. Khalifa tested the module first through AGMD configuration. The temperature range varied between 50$80{ }^{\circ} \mathrm{C}$ and the parameters on which it was based were: the width of the air layer, the width of the water layer, the feed rate, the salt concentration in the feed, the feed rates [21]. Figure 6 shows the results obtained for the volume of permeate for the two types of configurations.

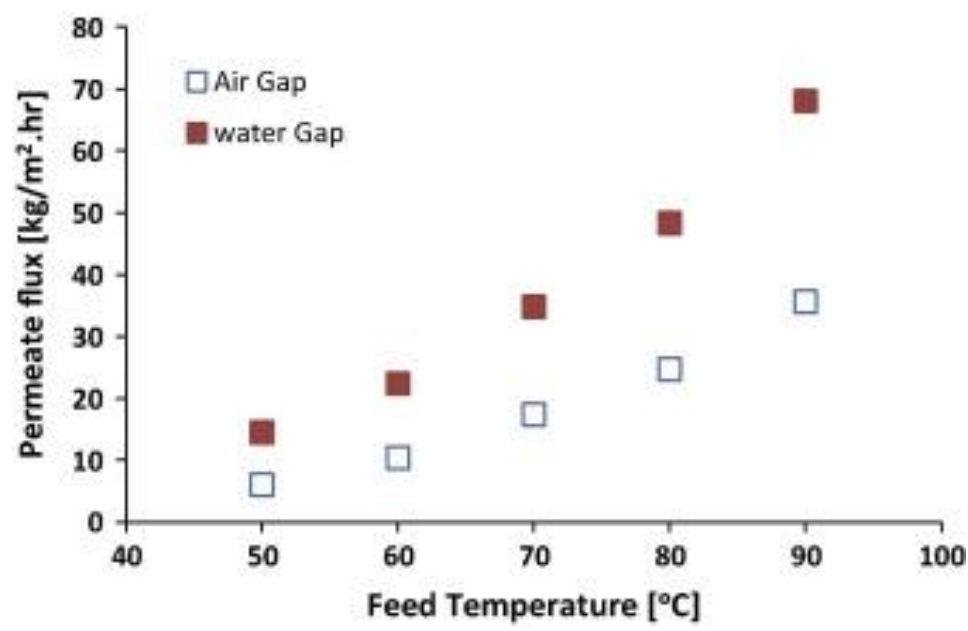

Fig. 6. The quantity of permeate depending on the feed liquid temperature for AGMD and WGMD [21].

The higher permeate volume is obtained in the case of water-gap distillation (WGMD). This can be explained by the fact that the temperature of the water layer is much more stable than the water layer, and this leads to the constant maintenance of the same thermal gradient and the condensation process, without pulsations, is done continuously and the collected water after vapors, increases the volume of the permeate in the end. 
With increasing temperature, the collected permeate flow increases exponentially. This is particularly noticeable in the WGMD configuration, since the permeate value at $90{ }^{\circ} \mathrm{C}$ at feed rate exceeds $70 \mathrm{~kg} / \mathrm{m}^{2} / \mathrm{h}$, and in the AGMD configuration the flow barely reaches $40-45 \mathrm{~kg} / \mathrm{m}^{2} / \mathrm{h}$ at the same temperature, as M. Essalhi and M. Khayet pointed out in the study, comparing the two types of configurations [20].

In the field of membrane distillation, the type and properties of the membrane play the most important role, so in the Essalhi and M. Khayet study, the permeate flow was improved by about $6.5 \%$ for the WGMD configuration [20].

Using the same membrane configuration, Francis et al reported an increase in vapor flow of up to $800 \%$ at different feed temperatures $\left(40-80{ }^{\circ} \mathrm{C}\right)$ [22]. The pores of the membranes used by Francis had dimensions between $0.24-0.25 \mu \mathrm{m}$ and the contact angle of 160 and $140^{\circ}$ [22].

\subsection{The permeate flow obtained, relative to the feed rate for the two configurations}

At $70{ }^{\circ} \mathrm{C}$ and at a concentration of $145 \mathrm{mg} / \mathrm{L}$ in the feed solution, Atia E. Khalifa [21] varied the flow rate between 1 and $6 \mathrm{~L} / \mathrm{min}$. It obtained a nearly double volume of permeate volume at the WGMD configuration than at AGMD (Figure 7).

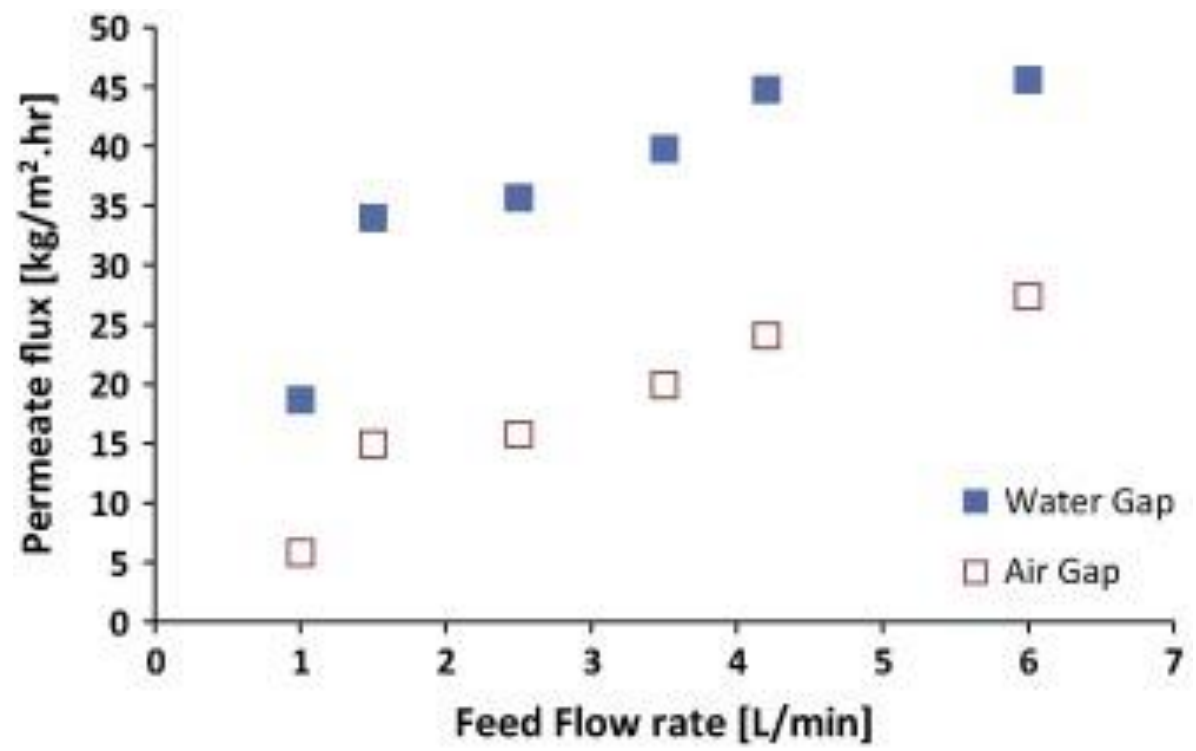

Fig. 7. Increase of permeate volume by feed rate [21].

With the increase of the feed rate, an increase in the volume of permeate is recorded, because in this context the pressure which leads to the forced distillation process increases. This is particularly noticeable in the WGMD (Figure 7, colored blue), where the flow of permeate can reach $45 \mathrm{~L} / \mathrm{m}^{2} / \mathrm{h}$. For air-to-air distillation (AGMD), the permeate flow can be reduced by half, regardless of the volume of liquid from the feed.

\subsection{Effect of cooling water flow on permeate volume}

The cooling water temperature in this study was maintained at $24{ }^{\circ} \mathrm{C}$ and the hot water temperature at $80{ }^{\circ} \mathrm{C}$. At the same concentration of $145 \mathrm{mg} / \mathrm{L}$ but with a feed rate of $1.5 \mathrm{~L} / \mathrm{min}$, Atia E. Khalifa [21] obtained the following permeate volume results for both membrane configurations, as shown in Figure 8.

In Figure 8, it is clear mentioned that the membrane efficiency is greater for water-gap distillation (WGMD), irrespective of the feed liquid is cold or hot water. Here it can be concluded that the properties of the water in the intermembrane layer are different from those of the air, and in the field of membrane distillation, these properties make a significant difference between the desalination methods used in the process. 


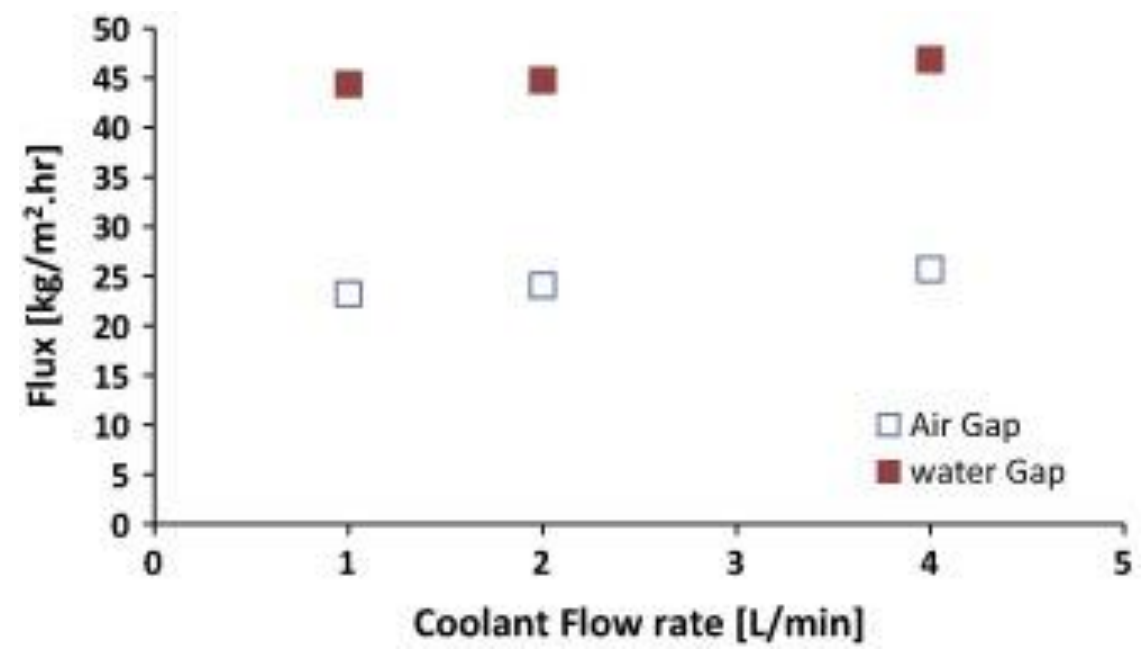

Fig. 8. Flow of permeate according to the cold water supply flow [17].

\subsection{The influence of the salt concentration in the supply water on both configurations}

In the study, Atia E. Khalifa used different salt concentrations, from 0 to $60 \mathrm{mg} / \mathrm{L}$ of $\mathrm{NaCl}$, varying two feed water temperatures, respectively 70 and $80{ }^{\circ} \mathrm{C}$. The flow rate was different, so cold water entering the module recorded $1.5 \mathrm{~L} / \mathrm{min}$ and the cold water flow, $2 \mathrm{~L} / \mathrm{min}$. It found a permeation decline due to the polarization phenomenon of the concentration [21]. Thus, at the concentration of $60 \mathrm{~g} / \mathrm{L}$ of NaCl, in the case of the WGMD configuration and at $70{ }^{\circ} \mathrm{C}$, the flow decreased, reaching a value of $25 \mathrm{~kg} / \mathrm{m}^{2} / \mathrm{h}$, respectively decreasing by almost $42 \%$ (Figure 9a).

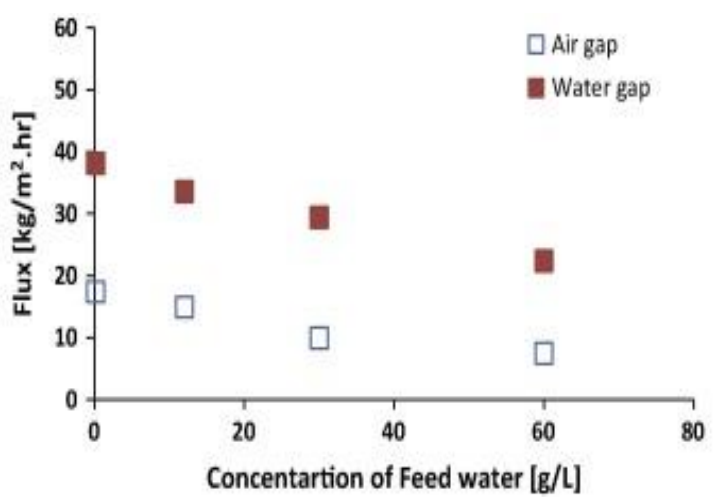

(a) Feed water at $70^{\circ} \mathrm{C}$

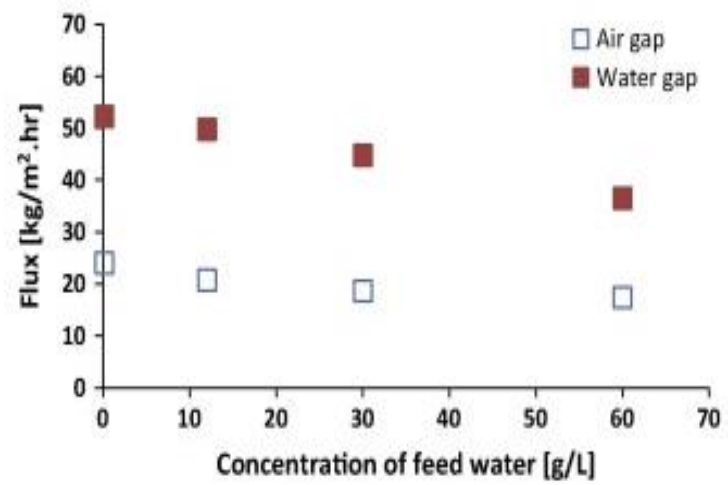

(b) Feed water at $80^{\circ} \mathrm{C}$

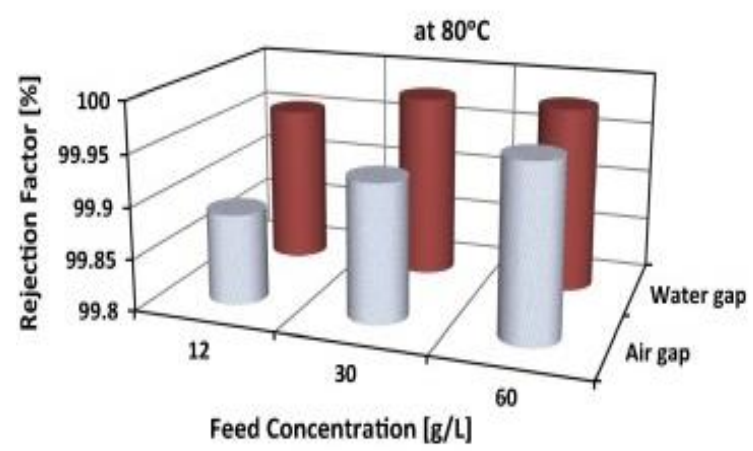

(c) Salt rejection factor at different feed concentrations

Fig. 9. a) and b): Influence of the feed concentration at 70 and $80^{\circ} \mathrm{C}$ on the permeate flow; c): the salt rejection factor by the membrane [21]. 
In the AGMD configuration, although the flow of permeate was lower than in the other configuration, it decreased by almost $58 \%$. The situation is different at $80{ }^{\circ} \mathrm{C}$ (Figure 9b): the percentage of decrease of permeate flow for both configurations decreases significantly.

This demonstrates that in order to obtain as much permeate as possible, a high temperature is the best solution especially when the salt concentration in the feed water is high. These results lead to the conclusion that salt rejection reached $99.98 \%$ (Figure 9c), which means that this type of membrane is not only resistant to high temperatures but retains almost all the salt, regardless of the concentration introduced into the supply water [21].

The feed concentration largely influences the decrease or increase of permeate flow. This is also evident in figure 9 where, with increasing feed concentration, the flow decreases. However, increasing the temperature from $70^{\circ} \mathrm{C}$ to $80^{\circ} \mathrm{C}$ causes the flow of permeate to rise to $52-53 \mathrm{~L} / \mathrm{m}^{2} / \mathrm{h}$ in the case of WGMD distillation. And the salt rejection factor shows a performance for the distillation membrane by the water layer method, reaching a value slightly below $100 \%$.

\subsection{Effect of the water / air layer width inside the membrane module}

Francis et al. Have specified that the flow of permeate increases with increasing the width of the water or air layer [22].

The results obtained by Atia E. Khalifa [21] disputed Francis' s words [22] because Atia E. Khalifa achieved clear results, which affirms and demonstrates that an increase in the space between the components of the membrane module and the increase of the gasket thickness, especially at high temperatures, lead to a decrease in flow of permeate. The latter obtained a clear hypothesis that in the AGMD configuration, the permeate flux drops almost doubled than in the other configuration when the thickness of the layer doubles (from 4 to $8 \mathrm{~mm}$ ) (Figure 10) [21].

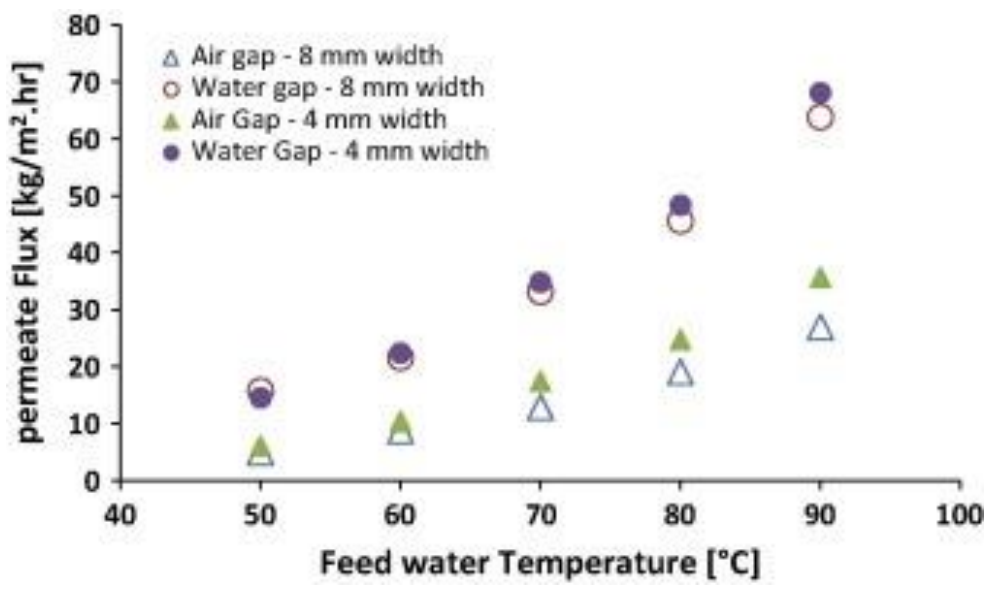

Fig. 10. Influence of air and water layer thickness according to supply temperature for WGMD and AGMD [21].

Decreasing the flow of permeate due to the increase of the thickness of the space in the module (irrespective of the water or air layer) can be explained in the following way: during the distillation process, throughout its duration, if the intermebranaire space increases, there can be many changes temperature which may disrupt the deployment under the best conditions. In other words, it is thermal transfer between cold and hot liquids.

\subsection{Influence of membrane support material}

The study presented by Atia E. Khalifa considered the influence of the membrane support material on the permeate flow obtained. In other words, a comparison was made between the permeate obtained when the support plate was PVC and when it was replaced with one of the brass.

At the 4 and $8 \mathrm{~mm}$ thickness of the air and water layer, a feed rate of $1.5 \mathrm{~L} /$ min was used, the temperature varied between 50 and $90{ }^{\circ} \mathrm{C}$. The results obtained are presented in Figure 11 [17]. 


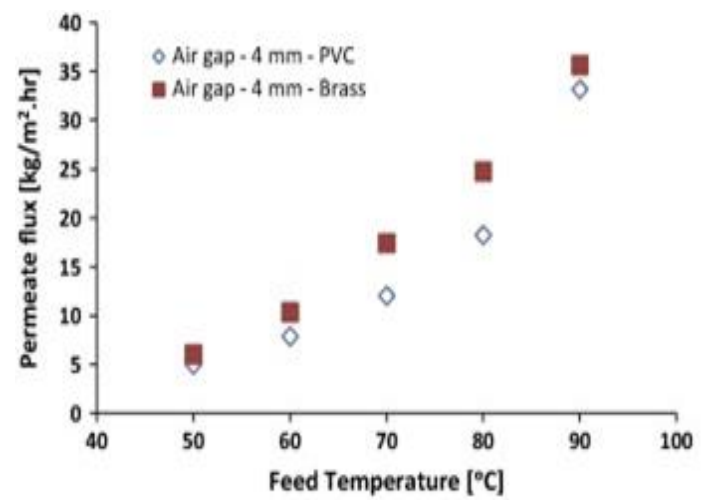

(a) $4 \mathrm{~mm}$ air gap

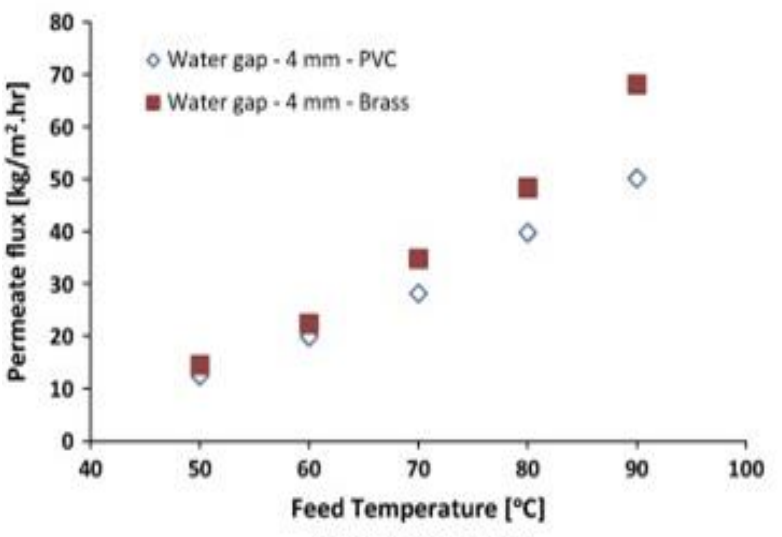

(c) $4 \mathrm{~mm}$ water gap

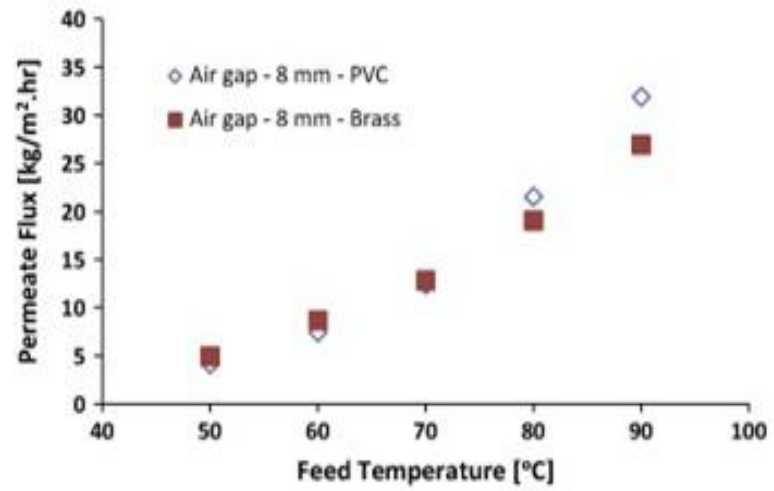

(b) $8 \mathrm{~mm}$ air gap

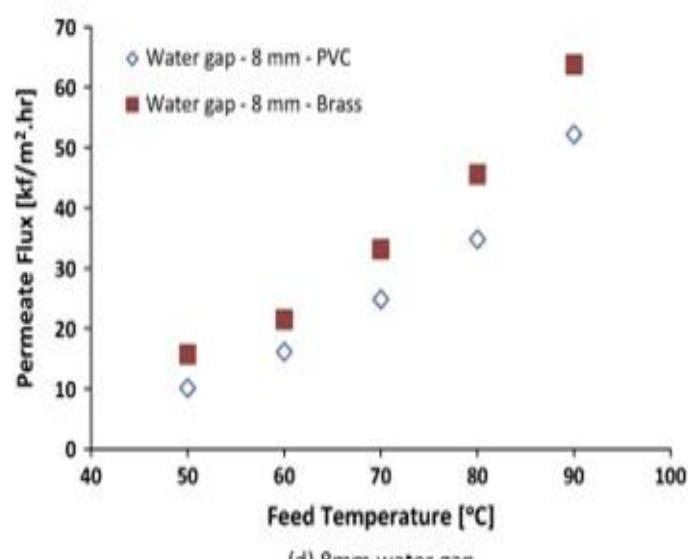

(d) $8 \mathrm{~mm}$ water gap

Fig. 11. Influence of membrane support plate material on permeate [21].

Figure 11 demonstrates that the use of brass plate is more efficient, since in this case the volume of permeate increases, regardless of the thickness of the layer. This is visible in both configurations.

\subsection{Air / water layer temperature for WGMD and AGMD configurations}

In response to the different inlet flow temperature, the temperature between the cold and the hot part of the inside of the module was monitored by means of thermocouples. At an input rate of $1.5 \mathrm{~L} / \mathrm{min}$ and $145 \mathrm{mg} / \mathrm{L}$, the emphasis was on recording the temperature at two thicknesses of the space, namely 4 and $8 \mathrm{~mm}$ [21].

It has been found that at temperatures lower than $60{ }^{\circ} \mathrm{C}$ in the feed, the room temperature for both configurations is the same, both at the $4 \mathrm{~mm}$ and $8 \mathrm{~mm}$ gap thicknesses. At room temperature above $60{ }^{\circ} \mathrm{C}$, in the case of WGMD, the room temperature drops slightly (by 2-3 ${ }^{\circ} \mathrm{C}$ ) (Figure 12), when the space thickness was $4 \mathrm{~mm}$ but with the increase in the thickness of the room, temperature increases (only in the WGMD case).

The conclusion here is that with the increase of the feed temperature, respectively the increase of the thickness of the space decreases the temperature of the water space and decreases and the permeate flow, which means the mass transfer potential due to the increase of the temperature gradient on the sides of the membrane [21].

As stated in point 3.6. regarding the influence of the material of the membrane support plate, the material from which the plate is made has a certain influence on the final product, respectively on the permeate. In other words, at $90{ }^{\circ} \mathrm{C}$, for PVC, the air space temperature (AGMD) reaches $67^{\circ} \mathrm{C}$. 


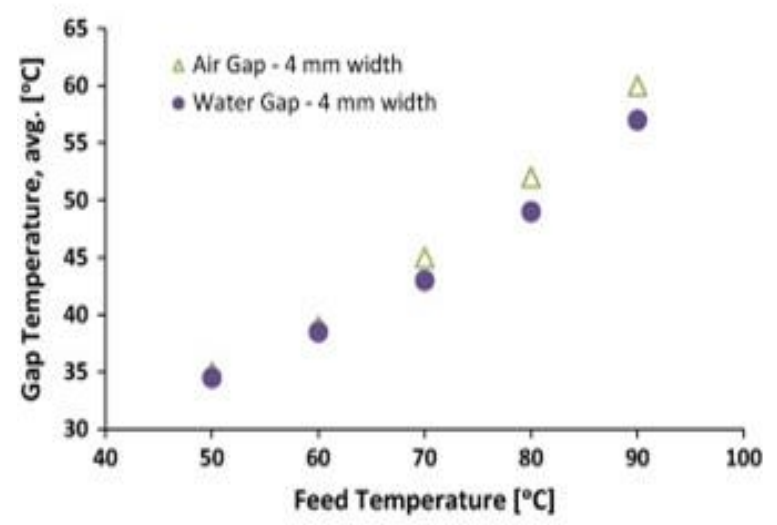

(a) $4 \mathrm{~mm}$ gap

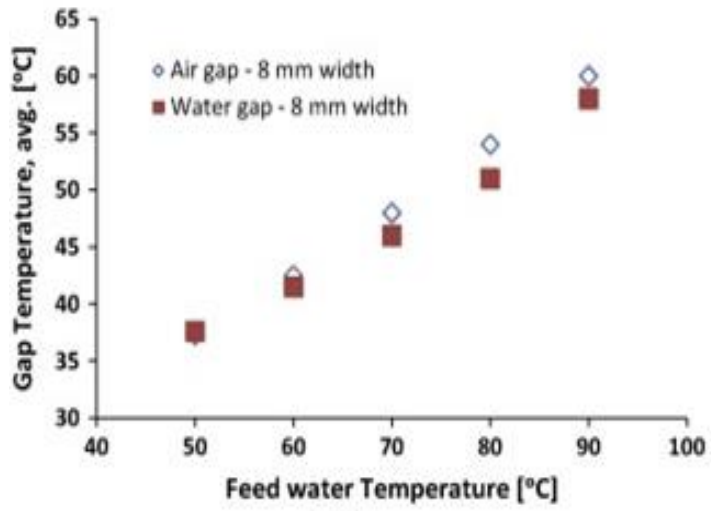

(b) $8 \mathrm{~mm}$ gap

Fig. 12. Temperature variation of the space in the mode according to the supply temperature [21].

In the case of the brass plate, the room temperature was reduced by up to $6{ }^{\circ} \mathrm{C}$ under the same conditions, demonstrating once again that the temperature of the space between the components of the membrane module decreases in the case of WGMD (Figure 13) [21].

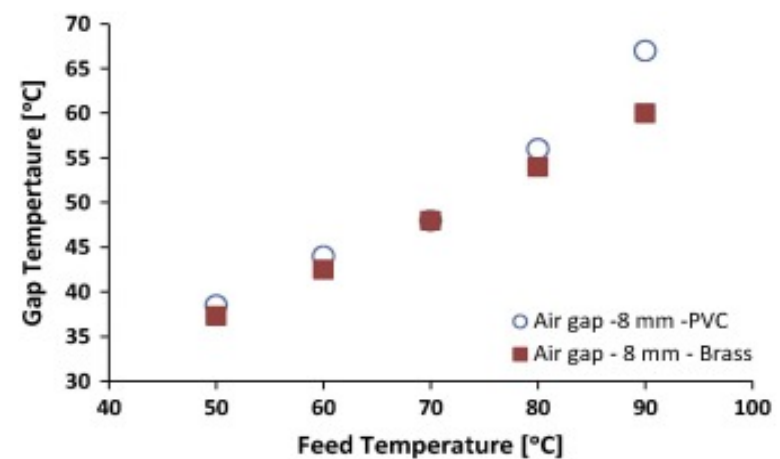

(a) $8 \mathrm{~mm}$ air gap

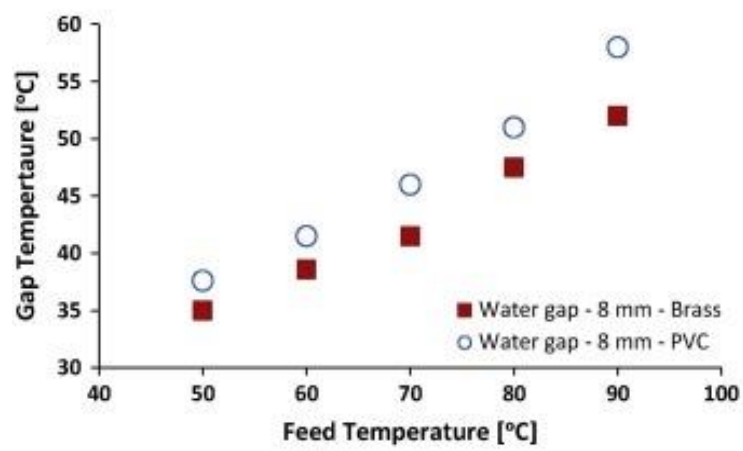

(b) $8 \mathrm{~mm}$ water gap

Fig. 13. Variation of air and water space temperature at $8 \mathrm{~mm}$ thickness using brass and PVC plate [21].

\section{CONCLUSIONS}

The study by Atia E. Khalifa took into account the comparison between seawater desalination by the air-bed distillation method and water layer. He wanted to prove by which of these two methods, the PTFE membrane is more efficient in terms of volume permeate, energy consumption, etc.

Experimenting the membrane under the same conditions, he watched the influence of the temperature in the incoming fluid on the space between the components of the membrane module, following the temperature of this space varies for both water and air space. At the same time, Atia E. Khalifa watched the influence of the cold and hot water flow, the structure of the membrane support material.

Following experiments with the same type of membrane, under the same working conditions for both types of configurations, the results obtained clearly established that the WGMD (water-layer distillation membrane) method is more effective, not only because of the increase in the volume permeate. Another reason is that salt can be retained at $99.98 \%$ and, as stated in this study, doubling the thickness of space between membrane 
components almost doubles the volume of permeate but also decreases the temperature inside that space. In other words, as the author has stated, WGMD distillation is more efficient at lower feeder temperatures [21].

Also in this experiment, the desalination performance by these methods, regardless of configuration, was also given by the material from which the support plate of the membrane support was made, and it was proved that the brass is much better than the PVC plate [21].

As in any study on the use of distillation membranes, as the concentration of the feed solution increases, the flow of permeate decreases over time as a result of polarization of the concentration. Atia E. Khalifa found that the PTFE membrane had a very high durability and the efficacy demonstrated in the study revealed a high salt rejection factor of $99.98 \%$, up to a feed concentration of $60 \mathrm{~g} / \mathrm{L}$ [21].

The results obtained from the experiments performed by the above-mentioned authors provide evidence that encourages the implementation of strategies for the management and exploitation of membrane technologies used on an industrial scale.

At the same time, the graphs, containing the data recorded during the experiments show and highlight the most important parameters through which the PTFE membranes (polytetrafluoroethylene) get the best performances. We observe throughout the study that the temperature is somewhat the most important parameter that most of the distillation process depends on.

The temperature depends also on the flow of the permeate obtained, the condensation process also depends, the concentration of the solutions in the water supply makes the water viscosity to be lower or higher depending on the temperature, etc.

However, the best results have shown that the membrane used in the water gap membrane distilation (WGMD) configuration can be within reach of future water purification strategies that bring benefits both from the economic point of view and on the environmental side.

\section{REFERENCES}

[1] Barsan, N., Nedeff, V., Temea, A., Mosnegutu, E., Chitimus, A.D., Tomozei, C., A perspective for poor wastewater infrastructure regions: a small-scale sequencing batch reactor treatment system, Chemistry Journal of Moldova, vol. 12, no. 1, 2017, p. 61-66.

[2] Barsan, N., Nedeff, V., Mosnegutu, E., Panainte, M., Heat balance components of a small sequencing batch reactor applied for municipal wastewater treatment, Environmental Engineering \& Management Journal, vol. 11. no. 12,2012 , p. $2133-2140$.

[3] Tirtoaca Irimia, O., Tomozei, C., Panainte, M., Mosnegutu, E.F., Barsan, N., Efficiency of filters with different filtering materials: comparative study in water treatment, Environmental Engineering \& Management Journal, vol. 11, no. 12, 2012, p. 2133-2140.

[4] Turcu, M., Bârsan, N., Moșneguțu, E., Dascălu, M., Chițimuș, D., Radu, C., Application of the flocullation process in the industrial wastewater treatment, Environmental Engineering \& Management Journal (EEMJ), vol. 15 , no. 3, 2016, p. 521-526

[5] Tataru, L., Nedeff, V., Bârsan, N., Panainte-Lehadus, M., Mosnegutu, E., Chitimus, D.A., Studies on the application of hollow fiber membranes in the field of ultrafiltration, Journal of Engineering Studies and Research, vol. 2, no. 4, 2016, p. 42-53.

[6] Camacho, L.M., Dumée, L., Zhang, J., de Li J., Duke, M., Gomez, J., Gray, S., Advances in membrane distillation for water desalination and purification applications, Water, vol. 5, 2013, p. 94-196.

[7] Alkhudhiri, A., Darwish, N., Hilal, N., Treatment of high salinity solutions: application of air gap membrane distillation, Desalination, vol. 287, 2012, p.55-60.

[8] Alkhudhiri, A., Darwish, N., Hilal, N., Membrane distillation: a comprehensive review, Desalination, vol. 287, 2012, p. 2-18.

[9] Banat, F.A., Simandl, J., Theoretical and experimental study in membrane distillation, Desalination, vol. 95, no. 1, 1994, p.39-52.

[10] Bandini, S., Sarti, G.C., Heat and mass transport resistances in vacuum membrane distillation per Drop, vol. 45, 1999, p.1422-1433.

[11] Bandini, S., Gostoli, C., Sarti, G.C., Separation efficiency in vacuum membrane distillation, J. Membr. Sci., vol. 73 no. $2-3,1992$, p. 217-229.

[12] Kurokawa, H., Kuroda, O., Takahashi, S., Ebara, K., Vapor permeate characteristics of membrane distillation, Sep. Sci. Technol., vol. 25, no. 13, 1990, p. 1349-1359. 
[13] Drioli, E., Calabro, V., Wu, Y., Microporous membranes in membrane distillation, Pure Appl. Chem., vol. 58, no. 12, 1986, p.1657-1662.

[14] Hitsov, I., Eykens, L., Schepper, W.D., Sitter, K.D., Dotremont, C., Nopens, I., Full-scale direct contact membrane distillation (DCMD) model including membrane compaction effects, J. Membr. Sci. vol. 524, 2017 , p. 245-256. (URL〈http://www. sciencedirect.com/science/article/pii/S0376738816317677, http://dx.doi.org/ http://dx.doi.org/10.1016/j.memsci.2016.11.044〉.).

[15] Alkhudhiri, A., Hilal, N., Air gap membrane distillation: A detailed study of high saline solution, Desalination, vol. 403, p. 179-186.

[16] Alkhudhiri, A., Darwish, N., Hilal, N., Membrane distillation: a comprehensive review, Desalination, vol. 287, 2012, p. 2-18.

[17] Khayet, M., Matsuura, T., Membrane distillation: principlesnd applications, Elsevier, Amsterdam, The Netherlands, 2011.

[18] Curcio, E., Drioli, E., Membrane distillation and related operations - a review, Sep. Purif. Rev. vol. 34, 2005, p. 35-86.

[19] Lawson, K.W., Lloyd, D.R., Membrane distillation, J. Membr. Sci., vol. 124, 1997, p. 1-25.

[20] Essalhi, M., Khayet, M., Application of a porous composite hydrophobic/hydrophilic membrane in desalination by air gap and liquid gap membrane distillation: a comparative study, Sep. Purif. Technol., vol. 133, 2014, p.176-186.

[21] Khalifa, A.E., Water and air gap membrane distillation for water desalination - An experimental comparative study, Separation and Purification Technology, vol. 141, 2015, p. 276-284.

[22] Francis, L., Ghaffour, N., Alsaadi, A., Amy, G., Material gap membrane distillation: a new design for water vapor flux enhancement J. Membr. Sci., vol. 448, 2013, p. 240-247. 